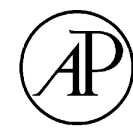

ACADEMIC

PRESS
Available online at www.sciencedirect.com

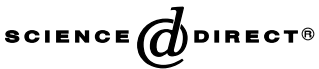

Journal of Vocational Behavior 62 (2003) 11-25

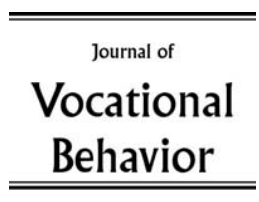

www.elsevier.com/locate/jvb

\title{
Career indecision: Three factors from decision theory
}

\author{
Veerle Germeijs* and Paul De Boeck \\ Department of Psychology, Catholic University Leuven, Tiensestraat 102, Leuven B-3000, Belgium \\ Received 8 August 2001
}

\begin{abstract}
Three factors of indecision are derived from decision theory: being insufficiently informed about the alternatives, valuation problems, and uncertainty about the outcomes. The three factors are studied in high school students' career decision process of choosing further studies. Using factor analysis, we found empirical evidence for a differentiation between the three theoretical sources of career indecision: an information factor, a valuation factor, and an outcomes factor, but only the valuation factor and the outcomes factor seem to associate empirically with career indecision. The importance of both factors for career indecision was further supported by their intermediate role between general indecisiveness and career indecision.
\end{abstract}

(c) 2002 Elsevier Science (USA). All rights reserved.

Keywords: Career indecision; Decision theory; General indecisiveness; Information; Valuation; Uncertainty about outcomes

\section{Introduction}

Career decision making is a complex process. As a result career counselors are confronted with a variety of difficulties that individuals encounter when making a career decision. In the literature, the construct of 'career indecision' is used to denote problems during the career decision-making process. Early research suggested that multiple forms of indecision may exist (Crites, 1969; Tyler, 1969). More recent research focused on the definition and determination of several types and categories

\footnotetext{
${ }^{*}$ Corresponding author. Fax: +32-16-326-144.

E-mail address: veerle.germeijs@psy.kuleuven.ac.be (V. Germeijs).
} 
of career indecision (Wanberg \& Muchinsky, 1992). However, there is a lack of consistency and stability with regard to the dimensions of career indecision (Gati, Krausz, \& Osipow, 1996; Tinsley, 1992). Tinsley (1992) stated that "despite the research attention given this construct in the past decade, indecision remains an atheoretical construct about which relatively little is known" (p. 210). Accordingly, in this article, we relate research on career indecision to the decision-making process itself and develop a theoretical context for the construct of indecision from decision theory.

Within decision theory, normative as well as descriptive models are developed. Normative (or prescriptive) models provide guidelines for how people should make optimal decisions, whereas descriptive models are based on how people actually make decisions. This article relies on the normative approach to decision making. According to the normative decision theory (e.g., expected utility theory), the optimal choice is the one that maximizes the expected utility. The expected utility of an alternative is based on a combination of the value and probability of the outcomes that are anticipated from each alternative (Gati \& Asher, 2001). In the expected utility model, the decision problem is solved in different stages (Gati, 1986). First, a person has to identify and define the desirable goals (step 1) and weigh these goals by importance (step 2). Further, one has to identify which alternatives exist (step 3), after which each alternative is rated with respect to the opportunities it offers for satisfaction of each value (step 4). This rating is multiplied by the weight given to the value (its importance, step 5). For each alternative the sum of products of the importance and the opportunities is calculated (step 6). Finally, this sum is modulated by an estimate of the probability of success (or entry) for each option (step 7) (Gati, 1986). These seven steps result in an expected utility for each alternative. The optimal choice is the alternative with the largest expected utility.

Based on the normative decision theory, Pitz and Harren (1980) decomposed decision problems into four basic elements. (1) The first element of each decision problem is a set of alternatives. When deciding, a person should be aware of the available alternatives and be well acquainted with their characteristics. (2) The second element of a decision problem is a set of objectives or goals that the decision maker wants to achieve. When deciding, it helps to have a clear goal in mind and to be able to link it to the alternatives. (3) According to Pitz and Harren (1980), the third basic element of each decision problem is a set of outcomes that is associated with each choice. (4) Finally, the attributes of the outcomes are the fourth element in a decision problem. From the attributes of an outcome one can tell how much the outcome meets the objectives of the decision maker. The attributes of each outcome are in fact instruments for reaching the objectives.

Relying on decision theory and taking into account the four types of elements just mentioned, we can distinguish three theoretical sources of indecision during a decision process. The first source is lack of information, and it refers to one or a combination of the following: not having a view on the possible alternatives, not knowing the attributes of the alternatives, and not having enough information about the alternatives and their outcomes in order to evaluate their attributes with respect to the objectives. Lack of information about the alternatives is related to steps 3 and 
4 of the expected utility model discussed by Gati (1986) and to the first and fourth element of a decision problem as described by Pitz and Harren (1980). The second source is a category of valuation problems consisting of value unclarity, value conflict, and evaluative evenness. Value unclarity means that the goals can be unclear, i.e., the person may not know what he or she wants from the alternatives. Value conflict implies that separate goals can be realized in different alternatives without there being an alternative in which they are all combined. Finally, evaluative evenness means that the most preferred alternatives can be equally attractive in terms of the goals. The three valuation problems are necessarily reflected in the attributes: unclarity regarding the attributes to consider, no ideal combination of attributes that meets all objectives, and the alternatives being equally valued from their attributes. These problems are related to steps 1 and 2 in the expected utility model (Gati, 1986) and have implications for steps 5 and 6, too. They also refer to the second element in the decomposition of a decision problem (Pitz \& Harren, 1980). The third source is uncertainty about the outcomes arising from unpredictable events or limitations to one's capability to bring an alternative to a good end (Pitz \& Harren, 1980). In step 7 of the expected utility model (Gati, 1986) the decision maker has to estimate the probability of success and/or entry for each alternative. This step is related to uncertainty about the outcomes.

The distinction between the three sources of indecision is also related to the taxonomy of difficulties in career decision making developed by Gati et al. (1996). These authors conceptualized "lack of information about occupations" and "lack of information about self" as two possible categories of difficulties that may occur during the career decision process. Within each of the two information categories a distinction is made between difficulties associated with the present and difficulties associated with the future. The distinction between present and future when related to lack of information about occupations, resembles the distinction between our first and third source of indecision, being lack of information and uncertainty about the outcomes. Furthermore, lack of information about the self is related to value unclarity (second source) and to uncertainty about one's capability to bring a choice to a good end (third source).

The first and second source of career indecision, namely lack of information and valuation problems, correspond to some of the dimensions of career indecision distinguished in previous research. For example, need for career information and need for self-knowledge are two factors of the Career Factors Inventory (Chartrand, Robbins, Morril, \& Boggs, 1990). Two of the four factors in the Reasons dimension of the Career Decision Profile (Jones, 1989) are knowledge about occupations and selfclarity. Our third source - uncertainty about the outcomes-has not been distinguished in the literature as a separate factor. De Boeck (1999) indeed noted that this factor might be considered as a factor of information about the alternatives, namely what is the probability of their outcomes. However, since the estimation of the probability of an outcome is distinguished as a separate stage in the normative decisionmaking process, it is hypothesized in this study that people can encounter specific problems during the decision-making process because they are uncertain about the outcomes and thus about the future. On the contrary, lack of information about 
the alternatives and valuation problems are conceptualized in this study as problems related to the present.

The first purpose of the present study was to find evidence for the differentiation between the three theoretical sources of indecision in a career decision situation. To investigate the differentiation between the three sources we constructed a scale for possible sources of indecision during a career decision process. Career indecision was specified in this study as the indecision of high school students with regard to further studies. It is hypothesized that the three sources of indecision each correspond to a separate dimension when the items of the scale concerning sources of indecision are subjected to a factor analysis.

The second purpose of this study was to investigate the relation of the three indecision factors with career indecision. To measure career indecision, a scale was constructed with items expressing difficulties in the career decision process (Germeijs \& De Boeck, 2002). Descriptors for behavior which express difficulties in career decision making were based on existing scales of career indecision and general indecisiveness (Chartrand et al., 1990; Cooper, Fuqua, \& Hartman, 1984; Frost \& Shows, 1993; Jones, 1989) and on literature that describes general indecisiveness (Crites, 1969; Dosnon, Wach, Blanchard, \& Lallemand, 1997; Gati et al., 1996; Osipow, 1999; Wanberg \& Muchinsky, 1992). The following descriptors for difficulties in making decisions in general are distinguished (Germeijs \& De Boeck, 2002): (1) deciding takes a long time, (2) finding it difficult to make a decision, (3) not knowing how to make a decision, (4) feeling uncertain during the decision-making process, (5) delaying a decision, (6) avoiding a decision, (7) leaving a decision to someone else, (8) instability of a decision, (9) worrying about a decision that is made, (10) regretting a decision that is made, (11) calling oneself indecisive when confronted with decision situations. To measure career indecision, participants are asked to indicate the extent to which they were confronted with each of these difficulties during the career decision-making process.

The decision process as it will be investigated in this article is already in its later stages for the participants. Students in the last year of high school participated in the study during the second last month of the school year (May). Based on earlier research, it can be expected that at that time most of them had chosen a study. For example, Lacante, Berings, Schodts, De Fruyt, and Colla (1997) asked Belgian university students during their first year at the university about the point of time they had decided about their study at the university. The authors found that $78 \%$ of the university students indicated they had made a study choice before May in the last year of high school. Note that in Belgian universities one has to choose a specific study program from the first year on.

The role of the three factors may change during the course of the decision-making process. In a study on the role of information and valuation factors (source one and two) in career decision, De Boeck (1999) found that in the early stages of the choice process both the information and valuation factors correlated with indecision, whereas in later stages only valuation problems correlated with indecision. From that study, we may expect that lack of information does not play a role in the later stages of the decision process, so that only valuation problems 
and uncertainty about the outcomes would remain as important sources of career indecision.

The third purpose of this study was to investigate the role of general indecisiveness. In the literature, the concept of general indecisiveness is used to explain being undecided in a broad range of decisions. Unlike career indecision, which must be seen as a particular kind of indecision, general indecisiveness is to be seen as a broad characteristic. Based on the same descriptors for difficulties in making decisions that have been discerned earlier, we constructed an indecisiveness scale (Germeijs \& De Boeck, 2002). To measure general indecisiveness, people had to indicate to which extent they faced each of these problems when making decisions in general. The list of problems was the same as for career indecision, but the question about the problems refered to decisions in general.

We investigated whether the three indecision factors can explain the relation between career indecision and general indecisiveness. General indecisiveness is a personality characteristic that slows down the decision process and that is already present before the process starts (Gati et al., 1996). From the characteristics of general indecisiveness, it is expected that people who are general indecisive will encounter many problems in decision making. Therefore, general indecisiveness may be expected to contribute significantly to career indecision (Cooper et al., 1984). In this study, we investigated the process through which general indecisiveness associates with career indecision. It was hypothesized that general indecisiveness operates through the three sources of indecision, so that, when the intermediate statistical effects of these three sources on career indecision are removed, there is no longer a correlation between general indecisiveness and career indecision.

Three hypotheses were tested. (1) The three hypothesized sources of career indecision can each be identified as a factor in a factor analysis of a questionnaire with items to capture the three sources of indecision. (2) The three hypothesized sources of career indecision contribute to career indecision, except perhaps the lack of information source, since the decision process as it will be studied is already in its later stages for the participants in our study. (3) General indecisiveness operates through the three hypothesized sources of indecision for its effect on career indecision. In other words, the direct effect should not be significant if the effects of the three factors are taken into account. If the results concerning the second hypothesis indicate that lack of information does not contribute to career indecision, lack of information will not be included as an intermediate variable between career indecision and general indecisiveness in the third hypothesis.sectionMethod

\subsection{Procedure and participants}

Students of the sixth (and last) year in two high schools in the Dutch speaking part of Belgium participated in the study, during the month of May, which is the second last month of the school year. Only students, who were likely to continue studying after high school, could participate in the research. For others, the issue of career indecision specified as deciding on further studies was irrelevant. Participation in the study was anonymous. In total, 292 students received a set of questionnaires, and 
184 of them returned their questionnaires. For the analyses, the data of 10 students were not included because they were incomplete.

The students first answered the questions on general indecisiveness, followed by a questionnaire about career indecision and the sources of career indecision.

\subsection{Questionnaires}

The students received four different questionnaires: (1) one on general indecisiveness, (2) another on decision problems regarding the choice of further studies, containing the items on career indecision as well as the items on the three sources of career indecision, (3) one about self-esteem, and (4) a brief questionnaire about six different kinds of daily decisions. Only the first two questionnaires are important for this study.

General indecisiveness. To measure general indecisiveness, a 22-item Likert-type questionnaire was constructed on the basis of the eleven features that have been discerned earlier. For each feature, we formulated a positive and a negative item, to counteract response tendencies, so that the total number of items was 22. Each item was formulated as a statement for which the subjects had to indicate the extent of agreement on a 7-point scale going from (0) strongly disagree to (6) strongly agree. Germeijs and De Boeck (2002) performed a principal components analysis on the 22 items of the general indecisiveness scale to check whether the scale is unidimensional. The principal components analysis revealed five factors with eigenvalues larger than 1.00. The eigenvalues of these factors are 8.02, 1.72, 1.48, 1.13, and 1.06, the first eigenvalue being almost five times as large as the second eigenvalue. Using a scree test, a one-factor solution was preferred. Of the 22 items, only one item had a loading lower than .40. The internal consistency (Cronbach's $\alpha$ ) of this scale was .91. These analyses are based on the same sample as used in this study. A translation of the 22 items into English is given in Table 1. In the questionnaire the items were randomly ordered.

Career indecision. The career indecision scale is a mixed scale with items on career indecision and items on the three hypothesized sources of career indecision. The items on career indecision have been formulated parallel to those of the general indecisiveness scale, but now the students were asked to answer the questions with respect to their decision on further studies. Nevertheless, for seven items the formulation was slightly different (item 5: I would characterize myself as an indecisive person regarding this situation; item 14: I don't avoid making this decision; item 17: I don' t often change my opinion in this decision; item 19: I don't worry about this decision; item 20: I can't get this decision out of my mind; item 21: I often believe I have made/will make the wrong decision; item 22: I am sure I will not regret my decision). For the other items the words decisions and a decision in the general indecisiveness scale were simply replaced by the word this decision.

In total 17 items were constructed to measure the three hypothesized general sources of indecision. For the construction of the items, eight more specific possible sources of indecision were distinguished, in line with specifications that are made earlier of the three more general sources: (1) For lack of information about the 
Table 1

Items of the indecisiveness scale
1. I find it easy to make decisions
2. It is hard for me to come to a decision
3. I don't know how to make decisions
4. I know which steps to take when making a decision
5. I would characterize myself as an indecisive person
6. I don't hesitate much when I have to make a decision
7. While making a decision, I feel certain
8. While making a decision, I feel uncertain
9. It takes a long time to weigh the pros and cons before making a decision
10. I make decisions quickly
11. I delay deciding
12. I don't postpone making decisions to a later date
13. I try to avoid making a decision
14. I don't avoid situations where decisions have to be made
15. I tend to leave decisions to someone else
16. I cut the knot myself in a decision instead of leaving the decision to others
17. Once I have taken a decision, I stick to that decision
18. I often reconsider my decision
19. Once I have made a decision, I stop worrying about it
20. After making a decision, I can't get it out of my mind
21. After I have decided something, I believe I took the wrong decision
22. After making a decision, I don't regret the decision

alternatives there are three specifications: not knowing which alternatives are available, not knowing the characteristics of the alternatives, not being able to make the link between the characteristics of the alternatives and the objectives. (2) Also for value problems there are three specifications: value unclarity, value conflict, and evaluative evenness. (3) Finally for outcome uncertainty there are two specifications: having no idea what the outcome of choosing an alternative will be, and not knowing whether one is enough prepared to succeed in the study one considers to follow. For the first seven specific sources a positively and negatively formulated item was constructed to counteract response tendencies. For the last problem concerning preparedness, three instead of two items were constructed, one positively and two negatively formulated, so that the total number of items was 17. Each item was formulated as a statement for which the subjects had to indicate the extent of agreement on a 7-point scale going from (0) strongly disagree to (6) strongly agree. The 17 items are listed in Table 2.

\section{Results}

\subsection{Differentiation between three factors of career indecision}

To check whether the items that were constructed to measure the same source of career indecision (lack of information about the alternatives, valuation problems, uncertainty about the outcomes) are also based on the same factor in a correlational 
Table 2

Items concerning sources of career indecision

Knowing which alternatives exist

1. I don't have an overview of the different alternatives yet

2. I can list the alternatives

Knowing the characteristics of the alternatives

3. I don't know sufficiently the characteristics of the alternatives

4. I have an idea of the differences between the alternatives

Ability to make the link between the characteristics of the alternatives and the objectives

5. I don't know to which characteristics of the alternatives I have to pay attention

6. I know whether the characteristics of the alternatives correspond to the goals that I want to achieve

Value unclarity

7. I don't know what I want to achieve by making this decision

8. I know what I want to realize through this decision

Value conflict

9. I have the feeling that the goals I want to achieve don't match

10. The goals I want to achieve are not contradictory

Evaluative evenness

11. I have the feeling that one alternative tower above all the others

12. The alternatives are equally attractive

Having no idea what the outcome of choosing an alternative will be

13. I have a good view on how each possibility would end if it would be chosen

14. I don't know what the end of choosing an alternative will be

Not knowing if being enough prepared to succeed in the study one considers to follow

15. I don't know if I am prepared for the alternatives

16. I think I judge my study results of next year quite well

17. I am uncertain about my chance of success next year

sense, a confirmatory factor analysis was performed. Responses to negatively formulated items were reversed so that for all items a 0 represents problems in decision making and a 6 means there are no problems. The items were divided into seven pairs and one triad, consisting of the positively and negatively formulated items belonging to the same specific source of indecision (see the eight possible specific sources of indecision discussed earlier). For the confirmatory factor analysis the scores of the items belonging to the same specific source of indecision were summed. Two important reasons for working with sum scores are that sum scores are more reliable, and that factor analysis will be less influenced by the idiosyncratic wording of the individual items (Marsh \& O'Neill, 1984).

The first hypothesis concerned differentiation between the three hypothesized sources of career indecision. It is hypothesized that (1) the responses to the eight sums could be explained by three factors, (2) that each sum would have a nonzero loading on the factor it was designed to measure, and zero loadings on the other two factors, (3) the three factors would be correlated, and (4) the error/uniqueness terms of the eight sums would be uncorrelated. 
The model was estimated with LISREL 8 (Jöreskog, Sörbom, du Toit, \& du Toit, 1999) using the covariance matrix, the asymptotic covariance matrix, and maximum likelihood estimations. This procedure was proposed by Jöreskog et al. (1999) for the case of small sample sizes. Instead of using weighted least squares as an estimation method to deal with nonnormality, which is not a good idea when the sample size is small, the model was estimated by maximum likelihood, but the standard errors and $\chi^{2}$ statistic were estimated under nonnormality. The Satorra-Bentler scaled $\chi^{2}$ statistic was proposed as a measure of fit (Jöreskog et al., 1999). Based on Byrne (1998), beside the $p$ value of the $\chi^{2}$ statistic, we also used the Root Mean Square Error of Approximation (RMSEA). Browne and Cudeck (1993) have suggested that a RMSEA smaller than .05 indicates a good fit, and values as high as .08 represent reasonable errors of approximation in the population. The fit indices for the model with three factors (Model 1, called "three-factor model") are given in Table 3.

The results of the confirmatory factor analysis indicated that the three-factor solution fit the data quite well. The loadings of the eight sums on the factor they were designed to measure, were all statistically significant. The standardized factor loadings are given in Table 4. From these results it is clear that the eight specific sources of career indecision correspond to three differentiated factors, to be interpreted as information problems, valuation problems and uncertainty about the outcomes. The three factors correlated rather highly in Model 1. The correlation was .72

Table 3

Fit indices of the models

\begin{tabular}{lccll}
\hline Model & \multicolumn{1}{c}{$\chi^{2}$} & $d f$ & $p$ value $\chi^{2}$ & RMSEA \\
\hline 1. Three-factor model & 13.36 & 17 & .711 & .000 \\
2. One-factor model & 48.82 & 20 & .0003 & .095 \\
3. Effect on career indecision: 3 factors & 35.45 & 31 & .266 & .030 \\
4. Effect on career indecision: 2 factors & 35.03 & 32 & .326 & .024 \\
5. Indecisiveness - career indecision & 7.55 & 5 & .183 & .056 \\
6. Intermediate variables & 42.98 & 50 & .748 & .000 \\
7. Model 6+ direct path & 34.38 & 49 & .943 & .000 \\
8. All direct paths & 28.99 & 48 & .986 & .000 \\
\hline
\end{tabular}

Table 4

Factor loadings for the three-factor solution

\begin{tabular}{lccc}
\hline Sums of items on same specific source & F1 & F2 & F3 \\
\hline Not knowing which alternatives exist & .71 & & \\
Not knowing characteristics of alternatives & .88 & & \\
No link between alternatives and objectives & .78 & .78 & .65 \\
Value unclarity & & .51 & .74 \\
Value conflict & & & .63 \\
Evaluative evenness & & & \\
Not knowing outcome & & & \\
Not knowing whether enough prepared & & & \\
\hline
\end{tabular}


between the information and the valuation factor, .76 between the valuation and the outcomes factor, and .71 between the information and outcomes factor.

Given the high correlations among the three factors, an alternative model was estimated with only one factor that explained the responses to the eight sums (Model 2 ). The results of this analysis indicate that a one-factor solution does not fit the data well enough in an absolute sense (see the highly significant $\chi^{2}$ for Model 2 in Table $3)$. In a relative sense, the one-factor model is clearly inferior to the three-factor model. These results support the differentiation between the three sources of career indecision.

\subsection{Relation with career indecision}

The second hypothesis concerned the relationship of the three factors to career indecision. It is hypothesized that at least the valuation factor and the outcomes factor have a significant effect on career indecision. Possibly, the information factor has no effect, since the study concerns the later stages in the decision process.

To check first whether the 22 items of the career indecision scale could be seen as measures of the same underlying construct of career indecision, a principal components analysis was used. Responses to negatively formulated items were reversed so that for all items a response of 0 represents "being undecided." Three factors with an eigenvalue larger than 1.00 were obtained. The eigenvalues of these factors were $11.88,1.66$, and 1.02, the first eigenvalue being much larger than the second. Also using the scree test, a one-factor solution should be preferred. This factor accounted for $53.99 \%$ of the variance in the items. The loadings of the items for the one-factor solution were all larger than .50. The internal consistency (Cronbach's $\alpha$ ) for the 22-item scale was .96 .

To investigate the effect of the three factors on career indecision, the latent variable career indecision was added in the model with the three factors. The sum scores of the first 11 items and of the last 11 items in the career indecision questionnaire were used as two indicator variables for the latent variable career indecision. In the model specification, equality restrictions were formulated for the factor loadings and the error variances of the two indicator variables. The unstandardized factor loadings of the indicator variables were fixed to 1 in order to be able to test the measurement model. First, a model was estimated with the three factors having an effect on the latent variable career indecision. The fit indices of this model indicated a good fit (see Model 3 in Table 3). As expected, the effect of the information factor on the career indecision factor was not significant $(t(159)=.50, \mathrm{~ns})$, whereas the effect of the valuation factor and the outcomes factor were significant indeed $(t(159)=2.69, p<.01$ and $t(159)=2.28, p<.05$ respectively). Therefore, the path from the information factor to the career indecision factor was omitted from Model 3. The fit of this model is still good (see Model 4 in Table 3). The effect of the valuation factor and the effect of outcomes factor on career indecision were both significant $(t(159)=3.18, p<.01$ and $t(159)=2.38, p<.05$ respectively). The correlations between the three factors are about as high as in Model 1. 


\subsection{Intermediate variables between indecisiveness and career indecision}

The last purpose of this study was to investigate whether the three (or two) factors of career uncertainty are sufficient to explain the relation between general indecisiveness and career indecision. This result will tell us whether indecisiveness has an effect beyond the three (or two) factors, or whether it fully operates through the sources of uncertainty. Since the results of Models 3 and 4 indicated that the information factor did not seem to have an effect on career indecision, only the valuation factor and the outcomes factor were treated as intermediate variables.

To check whether indecisiveness has a significant effect on career indecision without the two factors as intermediate variables, a model was constructed with only two latent variables, namely indecisiveness and career indecision, with the former having an effect on the latter. The sum score of the first and last eleven items in the questionnaires were used as two indicator variables for the corresponding latent variable. In the model specification the unstandardized factor loadings of the indicator variables are fixed to 1, and equality restrictions are formulated for the error variances of the indicator variables that correspond to the same latent variable. The fit indices of this model (Model 5) are given in Table 3. As expected, the effect of indecisiveness on career indecision was significant $(t(166)=4.91, p<.01)$.

To investigate whether the relation between indecisiveness and career indecision can be explained by the two factors with an effect on career indecision, the two factors were modeled as intermediate variables between indecisiveness and career indecision. The latent variable indecisiveness, was added to Model 4 using two split-half measurements (as in Model 5). In the model specification, the unstandardized factor loadings of the split-half measurements corresponding to the same latent variable (career indecision, general indecisiveness) were fixed to 1 and equality restrictions were formulated for the error variances of the split-half measurements (again as in Model 5). It was further stipulated that the latent variable indecisiveness had an effect on each of the three possible factors of career indecision, with only the valuation factor and the outcomes factor having an effect on the latent variable career indecision. If the two factors suffice to explain the effect general indecisiveness has on career indecision, then there should not be a direct effect of indecisiveness on career indecision. Therefore, the direct path from general indecisiveness to career indecision was not included in this model.

The fit indices of the model (see Table 3, Model 6) indicated a good fit. In Fig. 1 this final structural model is shown. The contribution of indecisiveness to each of the three factors was significant: $t(157)=3.35, p<.01$ for the valuation factor; $t(157)=4.40, p<.01$ for the outcomes factor; $t(157)=2.60, p<.05$ for the information factor. Both the effects of the valuation factor and the outcomes factor on career indecision were significant: $t(157)=2.89, p<.01$ and $t(157)=2.12, p<.05$.

Two alternative models were estimated in order to find further evidence for the hypothesis that the three factors can be seen as mediators between general indecisiveness and career indecision. In the first alternative model (Model 7), the direct path from general indecisiveness to career indecision was added to Model 6. The fit indices of the alternative model (see Table 3, Model 7) indicated a good fit. However, the 


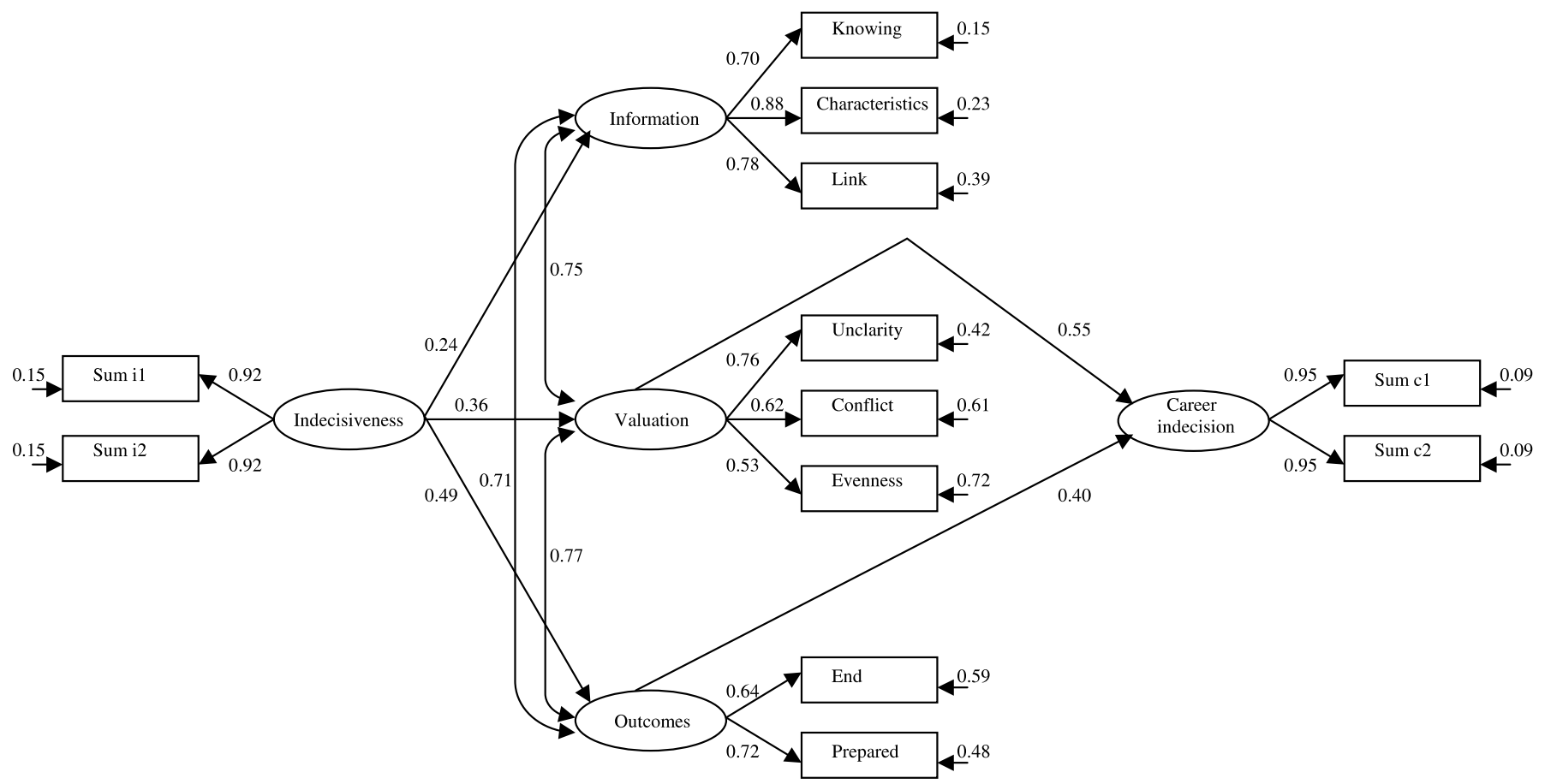

Fig. 1. Final model: indirect effect of general indecisiveness on career indecision via valuation problems and uncertainty about the outcomes (standardized solution). 
path from general indecisiveness to career indecision was not significant $(t(157)=-.22$, ns). Nonsignificant parameters can be considered unimportant to the model. According to Byrne (1998) they should be deleted from the model in the interest of scientific parsimony. To compare Models 6 and 7, the Parsimony Goodness-of-Fit Index (PGFI) was used. In this criterion the statistical goodnessof-fit (as measured by the Goodness-of-Fit index) as well as the complexity (i.e., number of estimated parameters) are considered. Thus the PGFI takes into account the parsimony of the hypothesized model in the assessment of overall model fit (Byrne, 1998). The Goodness-of-Fit indices of Models 6 and 7 were the same $(\mathrm{GFI}=.94)$. However, taking into account the parsimony of the model, Model 6 has a better fit than Model 7 (PGFI of Model $6=.60$; PGFI of Model $7=.59$ ). These results suggest that the direct path from indecisiveness to career indecision be deleted. In the second alternative model (Model 8), all three factors as well as general indecisiveness have direct paths to career indecision, without general indecisiveness having an effect on the three factors. The fit indices of Model 8 indicated a good fit (see Table 3). However, the PGFI for Model 8 was smaller than it is for Model 6 ( 0.58 versus 0.60$)$, indicating a better fit of Model 6 when taking into account the parsimony of the models.

These results confirm the importance of the valuation problems and the uncertainty about the outcomes in two ways: as variables with a direct effect on career indecision, and as intermediates between general indecisiveness and career indecision.

\section{Discussion}

The results of this study show that when students have to make a career decision concerning further studies, three elements can be differentiated as possible sources of indecision. A factor analysis of items concerning several sources of career indecision has shown evidence for three factors that could be interpreted as an information factor, a valuation factor, and an outcomes uncertainty factor. The information factor refers to how well students feel informed about the alternatives, the valuation factor refers to valuation problems related to the objectives and the value of the outcomes, and the outcomes factor refers to uncertainty about the outcomes.

Career indecision of the students was only predicted by the valuation factor and the outcomes factor. From the study of De Boeck (1999), we could already expect that the information factor would not have an effect on career indecision in our study, since we studied the decision process only in its later stages. Unlike De Boeck (1999) we do not have direct evidence that the results for the information factor depend on the stage of the decision process, since we have data from only one point in time. Further research is needed with a longitudinal design, implying that career indecision is investigated at the beginning as well as at the end of the choice process.

Finally, evidence was found that the factors derived from decision theory are important enough to explain the relation between general indecisiveness and career indecision. In the hypothesis testing, only the valuation factor and the outcomes factor were included as intermediate variables in the analysis, because the information 
factor did not seem to have an effect on career indecision. It may be expected that in the beginning of the decision process the information factor has an effect and also partially explains the relation between general indecisiveness and career indecision. Further research is needed to investigate this hypothesis.

Summarized, these results show evidence that a complex problem like career indecision concerning further studies can be decomposed into three different components, of which two have an important effect on career indecision in the later stages of the decision process. Therefore, this study could have implications for career counseling. Decomposing the problem of career indecision into different components allows for more specific diagnostics and related counseling. Depending on the source of the indecision that plays a role for a given student, the focus of the counseling needs to be specified if one wants the counseling to be effective.

Several qualifications should be made with regard to the findings reported in this study. First, all the instruments used in this study are new. Some evidence has been found supporting the validity and reliability of the indecisiveness scale (Germeijs \& De Boeck, 2002), but these results are based on the same sample as in this study. Further research on the quality of all the instruments in other samples is needed before making strong conclusions about the factors of career indecision. Second, all variables in the path models were measured at the same point in time. Given the stability of the variables, the order presented in the path models (e.g., general indecisiveness precedes career indecision) cannot be used to draw causal inferences. Longitudinal studies are needed to further clarify the causal relation between general indecisiveness, the three sources of indecision, and career indecision. Finally, in this study the decision problems were studied in the context of choosing what to study after high school. To check whether the factors derived from decision theory could provide a framework for describing the structure of decision problems in general, it would be interesting to investigate the role of these same factors in other types of decision situations.

\section{References}

Browne, M. W., \& Cudeck, R. (1993). Alternative ways of assessing model fit. In K. A. Bollen \& J. S. Long (Eds.), Testing structural equation models (pp. 445-455). Newbury Park, CA: Sage.

Byrne, B. M. (1998). Structural equation modeling with LISREL, PRELIS, and SIMPLIS: Basic concepts, applications, and programming. Mahwah, NJ: Erlbaum.

Chartrand, J. M., Robbins, S. B., Morril, W. H., \& Boggs, K. (1990). Development and validation of the Career Factors Inventory. Journal of Counseling Psychology, 37, 491-501.

Cooper, S. E., Fuqua, D. R., \& Hartman, B. W. (1984). The relationship of trait indecisiveness to vocational uncertainty, career indecision, and interpersonal characteristics. Journal of College Student Personnel, 25, 353-356.

Crites, J. O. (1969). Vocational psychology. New York: McGraw-Hill.

De Boeck, P. (1999). Two factors of preference certainty in the process of choosing an educational program. European Review of Applied Psychology, 49, 23-28.

Dosnon, O., Wach, M., Blanchard, S., \& Lallemand, N. (1997). La mesure de l'indécision chez les lycéens: présentation de trois instruments [The measurement of indecision among high school students: A study of three scales]. L'Orientation Scolaire et Professionnelle, 26, 57-88. 
Frost, R. O., \& Shows, D. L. (1993). The nature and measurement of compulsive indecisiveness. Behaviour Research and Therapy, 31, 683-692.

Gati, I. (1986). Making career decisions. A sequential elimination approach. Journal of Counseling Psychology, 33, 408-417.

Gati, I., \& Asher, I. (2001). The PIC model for career decision making: Prescreening, in-depth exploration, and choice. In T. L. Leong \& A. Barak (Eds.), Contemporary models in vocational psychology: A volume in honor of Samuel H. Osipow (pp. 6-54). New Jersey: Lawrence Erlbaum.

Gati, I., Krausz, M., \& Osipow, S. H. (1996). A taxonomy of difficulties in career decision making. Journal of Counseling Psychology, 43, 510-526.

Germeijs, V., \& De Boeck, P. (2002). A measurement scale for indecisiveness and its relationship to career indecision and other types of indecision. European Journal of Psychological Assessment, 18, $113-122$.

Jones, L. K. (1989). Measuring a three-dimensional construct of career indecision among college students: A revision of the vocational decision scale-The Career Decision Profile. Journal of Counseling Psychology, 36, 477-486.

Jöreskog, K. G., Sörbom, D., du Toit, S., \& du Toit, M. (1999). LISREL ${ }^{\circledR}$ 8: New statistical features. Chicago, IL: Scientific Software International.

Lacante, M., Berings, D., Schodts, L., De Fruyt, F., Colla, A. (1997). Het studiekeuzeproces met betrekking tot het hoger onderwijs [The choice process of a study in higher education] (Rep. No. 75). Belgium, Leuven: K.U. Leuven, Center for Motivation and Time Perspective.

Marsh, H. W., \& O'Neill, R. (1984). Self description questionnaire III: The construct validity of multidimensional self-concept ratings by late adolescents. Journal of Educational Measurement, 21, $153-174$.

Osipow, S. H. (1999). Assessing career indecision. Journal of Vocational Behavior, 55, 147-154.

Pitz, G. F., \& Harren, V. A. (1980). An analysis of career decision making from the point of view of information processing and decision theory. Journal of Vocational Behavior, 16, 320-346.

Tinsley, H. E. A. (1992). Career decision making and career indecision. Journal of Vocational Behavior, 41, 209-211.

Tyler, L. E. (1969). The work of the counselor (3rd edn). New York: Appleton-Century-Crofts.

Wanberg, C. R., \& Muchinsky, P. M. (1992). A typology of career decision status: Validity extension of the vocational decision status model. Journal of Counseling Psychology, 39, 71-80. 